\title{
From Legalized to Legal English: The Challenge of ESP
}

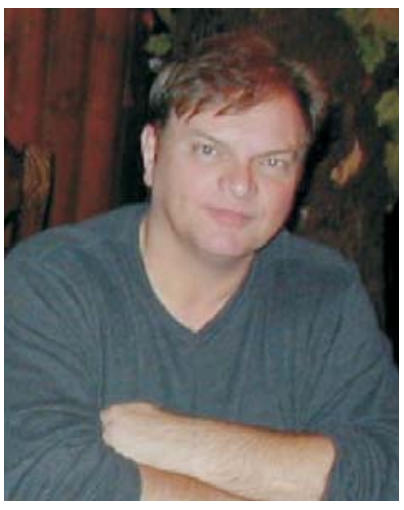

Charles Hall

1. Introduction: the Problem of Authentic Materials.

One of the recurring challenges that the ESP instructor faces is introducing authentic materials to students. Authentic materials provide students with realistic rhetoric models and accurate constructions; however, unless we carefully prepare our students, the linguistic complexity and lexical diversity of authentic material may discourage learners or may even quite literally be beyond the learners' ability. In this article we discuss a four-step process (based on a similar approach by Lee 2004) that takes us from schema activation to full cases and allows our students to gradually face the demands of authentic materials.

As an example of the process, we may wish to discuss search warrants in the American legal system. If we began our lesson by simply giving our students the following authentic quote from a relevant case from the U.S. Supreme Court, we might quickly lose the students in the complexity of legal English:

...At the same time, we recognized that the "flexible requirement of reasonableness should not be read to mandate a rigid rule of announcement that ignores countervailing law enforcement interests," id., at 934, and left "to the lower courts the task of determining the circumstances under which an unannounced entry is reasonable under the Fourth Amendment.” id., 936

Richards v. Wisconsin,-U.S.-, 117, S. Ct. 1416, 137 L.Ed.2d 615 (1997).

Our job is not to throw our students headlong into that genre; rather, we must guide our students through introductory steps that will ease their task. Unfortunately, there is an added complication that makes teaching legal English more challenging than other areas of ESP.

In most fields of ESP, such as engineering or genetics, the content of the "Specific Purposes” is basically the same in both target and source. Speaking about bridges in Armenian, Georgian or English is basically the same. However, in the case of legal English, this problem of authentic materials is exacerbated because the content of the target "Specific Purpose" [law] differs considerably from the content of the source Specific Purpose. For example, the nature of contracts in German law is quite different from that of American law.

Debra Lee and I use the term non-equivalent SPs [specific purposes] to describe these situations when the content is different (2000). Of course, the other fields in which the content is basically the same may then be described as equivalent SPs.

As Lee (2004) pointed out, we can make a good start at dealing with this issue by first introducing authentic legalized English texts to students rather than full-fledged 
legal texts. By legalized English we mean a text written for general audiences about a legal issue. Lee goes on to propose a three-step process: 1 . find a good legalized source about the case to be read, 2 . provide the students with an excerpt from the case, then 3 . provide the students with the complete case.

Although Lee's approach is effective, even before we begin with the legalized texts, we must do schema-activating activities that allow us to go into the subject. This "threestep plus one" approach seems simple, but it rests on using several tools which are crucial to modern ESP methodology.

\section{ESP Methodological Tools}

Genre analysis, content-based instruction [CBI], and corpus linguistics have given the ESP instructor strong tools to create exercises, materials, and courses that help the learner.

a. John Swales (1994) has provided us with a definition of genre [also called register or sub-registers by other researchers] which helps us investigate language and prepare appropriate materials. He writes that a genre is:

- a class of communicative events which has

- a shared set of communicative purposes and exhibits a certain

- prototypicality.

Thus, when we read the words "Once upon a time..." we instantly know we are dealing with the fairy tale genre. Likewise, the prototypical structure of the phrase "Court overturns conviction" allows us to predict that this phrase is a headline for a newspaper article. By looking at types of legal English (such as court testimony, international contracts, or municipal statutes), we can use the advances of genre analysis to pull out the salient features, both structurally and functionally, that we can share effectively with our students. For example, when reading a case, the student can be taught the prototypical moves [organizational structures] and collocations of an American case.

b. Content-Based Instruction [CBI] is now a widely accepted way to work with both content and language at the same time (Brinton, Snow, and Wesche 2003). CBI is especially important in non-equivalent ESPs since any work with comprehensible input that the students can have with the new content will aid them. By using authentic legalized English texts, we can increase the comprehensible content input. These texts, written for non-specialists in the target language, usually contain appropriate and accessible contextual clues, explanations, paraphrases, and direct instruction about the legal points discussed.

The standard three-fold approach to CBI of "into, through, and beyond" is especially useful for bringing the law student into the discourse community of expert legal readers. We will discuss this in more depth later.

c. Corpus linguistics allows us to use the speed and power of modern computers to explore subliminal patterns in millions of words of texts (Bowker and Pearson 2002). Corpus linguistics allows us to 'bypass' notoriously unreliable native-speaker intuition and use hard data to determine not what we think is said, but is actually said. 
By first using genre analysis to prepare corpora [a collection of texts] of specific genres or sub-genres (for example, rental agreements or letters to clients), we can examine the specialized corpora for lexical features, (such as collocations), syntactic features (preferred sentence structure), or sociolinguistic features ( "Do women actually use tag questions more than men?”). Given the ease with which these analyses can be carried out on common personal computers, we can even ask our students to discover the linguistic patterns themselves!

Let's now turn to the four steps we can use to gradually bring authentic legal materials into the classroom.

\section{3. "Into" - Schema Activation}

If we continue using the example of search warrants, we could begin with an activity that encourages our students to do a social analysis of search warrants.

We would start by asking our students if a police officer can simply walk into a house and start looking for illegal objects such as drugs or weapons. In many countries, the students would reply that the officer would need a "paper" or "order" allowing them to enter the house. Some may even know the term "search warrant" [most likely from television!].

Then using the information they've gained from films and television, ask them what the police have to do [generally!] before they enter a house even if they have a search warrant: they must knock on the door and announce themselves. (In films and television this is often heard as the stereotypical "Open up, it's the police!”).

Using an activity from Calleros (1999) we would show them two pictures which represent nice, clear facts: generally, we need a search warrant to search a house but not for a car. We would ask them in pairs or groups to give a social reason [not legal!] why a car would be different from a house.

Eventually, we would lead them to the legal phrase "expectation of privacy." We have "expectation of privacy" in a house (think of the English idiom "A man's house is his castle") but not in a car. Of course, there is no correct answer; rather we are looking for quality of argumentation.

Next we introduce the following two "what if's":

a. Would the police need a warrant for a "house on wheels" such as an RV [recreational vehicle] in which people live for months at a time while driving from place to place? Is there an expectation of privacy? Again, there is no correct answer; argumentation is most important.

b. Would it be different if a house were being moved on a trailer from one part of a city to another? [Remember houses in the U.S. are often made of wood and quite "light" in comparison to the stone houses found in many parts of the world.] After the students discuss this for a while, remind them that the house is "empty", no one is living in it while it's being moved. Is there an expectation of privacy in an empty house being driven down the street? This example is from a real case that went through several appeals with each side winning at times.

Now, the schema of search warrants is clearly activated. We can now turn to the three steps Lee suggests and modify them slightly. 


\section{4. “Through” - Legalized Texts and Excerpts}

a. From the introductory exercise, the students have the basic concepts and a few legal terms necessary to understand a legalized text. Using a search engine on the Internet, it would be simple to find an article on search warrants from a newspaper or news agency such as CNN. In fact, you could even use a television program [such as "Law and Order"] or documentary which deals with search warrants. Of course, you would wish to prepare the text by introducing key terms, structures and collocations before you give the students the legalized texts.

b. Then you would give them a section of the full case that they will finally be reading. Of course, you will need to 'rehearse' the facts of the case before you present the extract.

Let's return to the case we mentioned at the beginning of the article in which the police did NOT "knock and announce" before they entered the house. We can give the students this extract of legal English now and ask them to analyze it. This is from the Wisconsin_Supreme Court decision [which was appealed to the U.S. Supreme Court]:

State v. Richards, 201 Wis.2d 845, 549 N.W.2d 218 (1996).

...Richards argues that because the police failed to 'knock and announce' prior to entering his motel room to execute a search warrant, any evidence must be suppressed. This issue is simply stated: whether the Fourth Amendment allows a blanket exception to the general requirement of 'knock and announce' (the rule of announcement) for entries into premises pursuant to a search warrant for evidence of felonious drug delivery. We conclude that exigent circumstances are always present in the execution of search warrants involving felonious drug delivery, [such as] an extremely high risk of serious if not deadly injury to the police as well as the potential for the disposal of drugs by the occupants prior to the entry by the police. The public interests inherent in these circumstances far outweigh the minimal privacy interests of the occupants of the dwelling for which a search warrant has already been issued.

Once that 'prototypical' language of the decision and the key terms and collocations ('execute a search warrant' or 'felonious drug delivery') are explored through the tools of Corpus Linguistics, we can go in the final stage of CBI beyond.

\section{5. "Beyond" - The Full Case and Revisiting the Social Analysis}

Next, we can present the full case to the students. U.S. Supreme Court decisions are easily available on the Internet (http://supct.law.cornell.edu/supct/) and usually deal with a topic of high social interest, so they are a good choice. If you have access to a computer lab, you can take your students there, have them download the case so that they can work with it in a concordancer or just in a word processing program.

Finally, after the case has been read, you might wish to ask your students to go 'beyond' the case and write a response paper based on a question involving social analysis. For example, you might wish to ask "Is it really in the public interest to require search warrants when felonious drug delivery is suspected?” Likewise, you may wish to stage a debate in which you assign the side that students must represent, remembering that a successful lawyer must be able to argue both sides of an issue with equal facility. 
6. Conclusion

Authentic materials are essential in the ESP class, but those materials can be daunting to the beginning reader or student. By using the tools of CBI, Corpus Linguistics, and Genre Analysis, we can develop a four-step approach which allows us to activate appropriate schemata, introduce legalized texts, read full cases, and go beyond the reading to higher level analyses.

\section{References:}

1. Bowker L., Pearson J. Using Specialized Corpora. London: Routledge, 2002.

2. Brinton D. Snow M., Wesche M. Content-Based Second Language Instruction. Ann Arbor, University of Michigan Press, 2003.

3. Calleros C. Reading, Writing, and Rhythm: A Whimsical, Musical Way of Thinking about Teaching Legal Method and Writing. In: The Journal of the Legal Writing Institute, 1999, 5, p.2-22.

4. Hall Ch., Lee D. Current Trends in Legal English. (Paper presented at International TESOL), Canada, Vancouver, 2000.

5. Hunston S., Gill F. A Corpus-driven Approach to the Lexical Grammar of English. Amsterdam, Benjamins, 2000.

6. Lee D. Making the Leap from General to Legal English. In: The Essential Teacher: Compleat Links. TESOL, 2004, [http://www.tesol.org/pubs/magz/et/compleat/v01/03-04.html].

7. Lee D., Hall Ch., Hurley M. American Legal English. Ann Arbor, University of Michigan Press, 1999.

8. Lewis M. The Lexical Approach. UK, Hove, Language Teaching Publishers, 1993.

9. Swales J. Genre Analysis. London, Cambridge University Press, 1994.

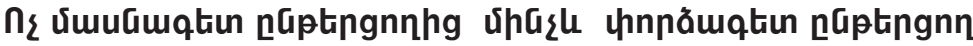

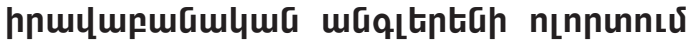

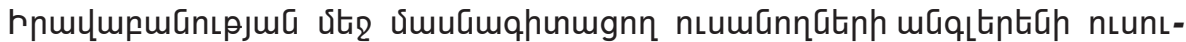

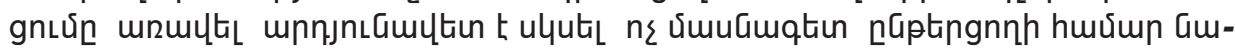

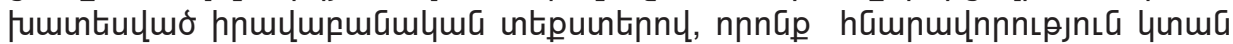

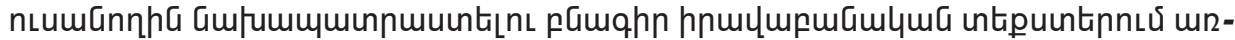

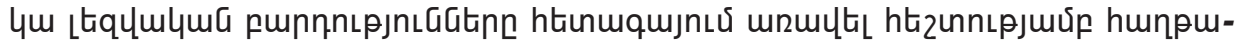

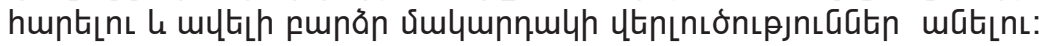

